UNIVERSITY OF NOTTINGHAM

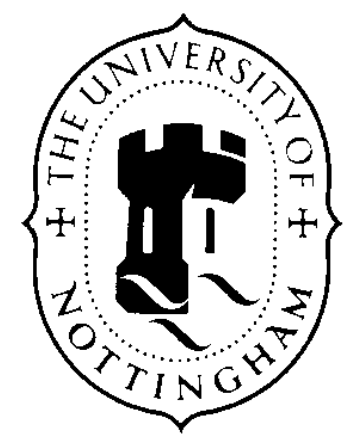

Discussion Papers in Economics

Discussion Paper

No. $10 / 07$

Social efficiency of entry with market leaders

Arijit Mukherjee

August 2010 


\title{
Social efficiency of entry with market leaders
}

\author{
Arijit Mukherjee \\ University of Nottingham and The Leverhulme Centre for Research in Globalisation and \\ Economic Policy, UK
}

August 2010

\begin{abstract}
We offer a new respective to the social efficiency of entry by considering an industry with a quantity setting leader and free entry of followers. We show that whether free entry with a homogeneous product is socially excessive or insufficient depends on the identity of the leader (which is either domestic or foreign), the marginal cost difference between the leader and the followers, and whether there are scale economies. In a closed economy, entry is socially excessive (insufficient) in the presence of scale economies if the marginal cost difference between the leader and the followers is small (large), but without scale economies, entry is always socially insufficient. In an open economy with the foreign leader, entry is always socially insufficient. Our results show concern to the anti-competitive entry regulation policies following the previous literature showing socially excessive entry in Cournot oligopolies with homogeneous products and perfectly competitive input sector.
\end{abstract}

Key Words: Excessive entry; Follower; Insufficient entry; Leader; Stackelberg competition JEL Classification: L13; L40; L50

Correspondence to: Arijit Mukherjee, School of Economics, University of Nottingham, University Park, Nottingham, NG7 2RD, UK

E-mail: arijit.mukherjee@nottingham.ac.uk

Fax: +44-115-951 4159 


\section{Social efficiency of entry with market leaders}

\section{Introduction}

What is the effect of entry on welfare in an oligopolistic industry? This question has attracted attention of the researchers for long time, and is very important for competition policies. It is well-known that free entry of firms in a Cournot oligopoly is socially excessive in the presence of homogeneous products and perfectly competitive input sector, and is often referred as the "excess-entry theorem". ${ }^{1}$ In different contexts and with sequential entry, Williamson (1968), Dixit and Stiglitz (1977), von Weizsäcker (1980), Perry (1984), Mankiw and Whinston (1986), Suzumura and Kiyono (1987), Okuno-Fujiwara and Suzumura (1993), Anderson et al. (1995) and Fudenberg and Tirole (2000) show excessive entry in the presence of scale economies, while Klemperer (1988), Lahiri and Ono (1988) and Ghosh (2007) suggest excessive entry without scale economies but in the presence of marginal cost differences. ${ }^{2}$ These works provide justifications for anti-competitive entry regulations, and may have influenced the policies of several countries.

As Vives (1988) suggests, whether entry is socially excessive is not of purely academic interest. In many countries, governments take actions to foster or deter entry into particular industries. For example, in the post-war period, preventing excessive entry was a guiding principle in the Japanese industrial policy (see, e.g., Suzumura and Kiyono, 1987 and Suzumura, 1995).

While the existing works provide important insights, they have been restrictive by considering firms choosing quantities simultaneously, thus ignoring the effects of dominant firms or market leaders. However, it is often found that some firms posses competitive

\footnotetext{
${ }^{1}$ Under excessive entry, social welfare reduces with entry. If entry is insufficient, social welfare increases with entry.

${ }^{2}$ Spence (1976) shows welfare reducing entry with asymmetric cost firms in a monopolistically competitive market, thus ignoring strategic interactions between the firms.
} 
advantage over others and become the market leaders, due to technological, historical or legal reasons, or just because entry was not possible at an earlier stage (Etro, 2008). For example, patent protection may help the innovators to become market leaders by providing competitive advantage over other firms.

Opinion differs on the minimum size of a dominant firm. Scherer (1980) discusses about a leading firm's market share of $40 \%$, while Landes and Posner (1981) suggest $80 \%$ or more. The European Union suggests that market shares of $80 \%$ show clear evidence of dominance and market share of $40-50 \%$ strongly implies the ability to exploit strategic advantage against rivals (George and Jacquemin, 1992). The US merger guidelines contain a "Leading firm proviso" based on a market share of at least 35\% (US department of justice, 1988).

There are several evidences of dominant firms or market leaders. For example, Pot Noodle brand, which is Unilever's original instant hot snack, is the UK \& Ireland's No. 1 Pot $\begin{array}{lllll}\text { Snack } & \text { with } & \text { a } & 77 \% & \text { market }\end{array}$ (http://www.unilever.co.uk/brands/foodbrands/Pot_Noodle.aspx). The big four supermarkets in the UK (Tesco, Asda, Sainsbury's and Morrisons) now account for three-quarters of the grocery market and about 7000 small or independent shops closed in London in the past 10 years (BBC News London, 28 July 2010: http://www.bbc.co.uk/news/uk-england-london10785782), which concern both the citizens and the policy makers. Two large insurance companies cornered $98 \%$ of the market in Hawaii 2007, and in California, the most competitive of the states surveyed, two insurance companies controlled $44 \%$ of the market (CNBC, 18 September 2009, http://www.cnbc.com/id/32918263).

As mentioned in Martin (2001), if there are dominant firms or market leaders, it is customary to consider Stackelberg competition instead of Cournot competition. Hence, the 
previous works analyzing welfare effects of entry under Cournot competition may not be appropriate in the presence of market leaders.

In this paper we offer a new perspective to the excess entry literature by considering free entry in an industry with a market leader. We consider an industry with a Stackelberg leader and large number of potential followers, who decide whether or not to enter the industry, where entry requires a fixed investment. In this framework, we show that whether free entry in an industry with a homogeneous product is socially excessive or insufficient depends on the identity of the leader (which is either domestic or foreign), the marginal cost difference between the leader and the followers, and whether there are scale economies. In a closed economy, entry is excessive (insufficient) in the presence of scale economics if the marginal cost difference between the leader and the followers is small (large), but, without scale economies, entry is always socially insufficient. In an open economy with the foreign leader, entry is always socially insufficient. Our results show concern to the anti-competitive entry regulation policies following the previous literature showing socially excessive entry in Cournot oligopolies with homogeneous products and perfectly competitive input sector. Hence, policies to foster entry might be needed designed in the presence of market leaders. ${ }^{3}$

If we consider that the Stackelberg leader is an innovator and knowledge spillover, which may the outcome of a weak patent system, creates entry of the followers, our results suggest that whether entry regulation is justifiable may depend on the patent regime. If a weaker patent system reduces the marginal cost of the followers, entry regulation may be justifiable if the patent system is very weak so that it creates a small marginal cost difference between the leader and the followers. However, if the patent system is sufficiently strong so that the marginal cost difference between the leader and the followers is sufficiently large, entry should be encouraged.

\footnotetext{
${ }^{3}$ Mukherjee (2007) compares welfare under monopoly and Stackelberg duopoly when the leader and the follower differ in terms of marginal costs. However, that paper does not consider free entry, set up cost that creates scale economies and social optimality of entry.
} 
Our paper complements the literature on insufficient entry in imperfectly competitive markets. Spence (1976) and Dixit and Stiglitz (1977) show insufficient entry in monopolistically competitive industries with product diversity. Cabral (2004) compares the welfare effects of entry between simultaneous and sequential entry for different degrees of product market competition and shows that, in case of sequential entry (which is relevant for the present paper), entry can be insufficient if the product market is characterized by (almost) Bertrand competition. So, excessive entry under Cournot competition remains in Cabral (2004). Ghosh and Morita (2007a, b) show the possibility of insufficient entry in a vertical structure where entry occurs in the upstream market. Mukherjee and Mukherjee (2008) show insufficient entry in the presence of technology licensing between the incumbent and the entrant. Mukherjee (2010) shows insufficient entry in the presence of external economies of scale, thus focusing on the positive externalities created by entry. We ignore all the effects which create insufficient entry in the above-mentioned papers. The presence of a market leader is responsible for insufficient entry in our analysis. Thus, we suggest that if there are market leaders, antitrust authorities may need to take policies to encourage entry in an industry with quantity setting firms, homogeneous products, no technology transfer, perfectly competitive input markets and no positive externalities of entry.

Lim (2010) and Marjit and Mukherjee (2010) show insufficient entry in an open economy with Cournot competition and scale economies. Our analysis for an open economy shows that their insufficient entry results remain with market leaders, with and without scale economies.

The remainder of the paper is organized as follows. Section 2 describes the model and shows the results. Section 3 concludes. 


\section{The model and the results}

Consider a firm, which has invented a technology for a product, and can produce the product at the marginal cost $c_{l}$, which is assumed to be zero for simplicity. We call this firm as leader. The leader enters the industry by incurring a fixed cost $k$.

We assume that the knowledge of the leader spills over to large number of potential entrants in the market. Each entrant can produce the product at a marginal cost of production $c(>0)$. Hence, $c$ measures the marginal cost difference between the leader and the entrants, and may capture the strength of the patent system and the complexity of the technology, which affect the extent of knowledge spillover. However, if a follower wants to produce the product, it needs to enter the market by incurring a fixed cost $k$. If an entrant enters the market, we call that entrant as a follower.

We consider the following game. At stage 1, the leader enters the market. At stage 2, the entrants decide whether to enter the market or not. If there is no entry, the leader produces like a monopolist at stage 3 , and the profit is realized. If there is entry at stage 2 , the leader behaves like a Stackelberg leader and the followers behave like Stackelberg followers at stage 3, and the profits are realized. We solve the game through backward induction.

We assume that the inverse market demand function for the product is

$$
P=a-q,
$$

where $P$ is price of the product and $q$ is the total quantity sold.

In our analysis, we will assume that

(i) $c<\frac{a}{2+n} \equiv c^{\max }$, which will ensure positive outputs of all firms producing in the market, and 
(ii) $\frac{(a-3 c)^{2}}{16}>k$, which ensures that at least one follower enters the market. This assumption also ensures that the net profit (i.e., the operating profit minus the fixed cost) of the leader is positive.

If $n$ followers enter the market, the ith follower maximizes the following expression to determine its output, where $i=1,2, \ldots, n$ :

$$
\underset{q_{i}}{\operatorname{Max}}(a-q-c) q_{i}
$$

Given the output of the leader as $q_{l}$, the output of the $i$ th follower is

$$
q_{i}^{*}=\frac{a-c-q_{l}}{n+1} .
$$

Since the leader behaves like a Stackelberg leader, it maximizes the following expression to determine its output:

$$
\underset{q_{l}}{\operatorname{Max}}\left(a-q_{l}-\frac{n\left(a-c-q_{l}\right)}{n+1}\right) q_{l}
$$

The equilibrium output of the leader can be found as

$$
q_{l}^{*}=\frac{a+n c}{2}
$$

Using (5), we then get the equilibrium output of the ith follower as, $i=1,2, \ldots, n$

$$
q_{i}^{*}=\frac{a-c(2+n)}{2(n+1)}
$$

It follows from (5) and (6) that as the marginal cost difference between the leader and the followers increases, i.e., as $c$ increases, it increases the output of the leader and reduces the outputs of the followers. On the balance, for a given $n$, it reduces the total output, which is $q^{*}=\frac{a(2 n+1)-n c}{2(n+1)}$.

The net equilibrium profits of the leader and the $i$ th follower, $i=1,2, \ldots, n$, are respectively 


$$
\pi_{l}^{*}=\frac{(a+n c)^{2}}{4(n+1)}-k \quad \text { and } \quad \pi_{i}^{*}=\frac{(a-c(2+n))^{2}}{4(n+1)^{2}}-k
$$

The equilibrium number of followers, denoted by $n^{*}$, is then determined by the following zero profit condition:

$$
\frac{\left(a-c\left(2+n^{*}\right)\right)^{2}}{4\left(n^{*}+1\right)^{2}}=k .
$$

It is immediate from (8) that as $c$ increases, it reduces the number of followers in the market, thus increasing market concentration.

Since the leader takes the entry decision before the followers, it is immediate that the entry decisions will effectively be for the followers, which is shown by (8). It is also easy to see that if $c>0$ and (8) holds, the leader has the incentive to enter the market.

Now we want to determine the socially optimal number of followers. We assume that the objective of the social planner is to select the number of followers (since the leader will enter and has no reason to restrict its entry because of its lower marginal cost compared to the followers) that maximizes welfare, given that the firms behave like Stackelberg leader and followers. Even if the social planner may affect the number of followers, he cannot influence the firms' behavior in the product market. Hence, first the social planner determines $n$, after which the Stackelberg leader and the followers take their output decisions.

If there are $n$ followers, the outputs and the profits are shown in (5)-(7). The social planner determines the number of followers to maximize welfare, which is the sum of "total profits of the leader and the followers, and consumers surplus", where consumer surplus is $\frac{\left(q^{*}\right)^{2}}{2}$. Hence, the socially optimal number of followers is determined by maximizing the following expression:

$$
\underset{n}{\operatorname{Max}} \frac{(a+n c)^{2}}{4(n+1)}+\frac{(a-c(2+n))^{2}}{4(n+1)^{2}}+\frac{(a(2 n+1)-n c)^{2}}{4(n+1)^{2}}-(n+1) k
$$


The following expression gives the socially optimal number of followers:

$$
\frac{a^{2}-a c(3+n)+c^{2}[4+n(7+2 n(3+n))]}{4(n+1)^{3}}-k=0 \text {. }
$$

Therefore, entry is insufficient (excessive) if left hand side (LHS) of (10) is positive (negative) at the free entry equilibrium number of firms shown in (8). We get that LHS of (10) is positive (negative) at the free entry equilibrium number of firms if

$$
c>(<) \frac{n^{*} a^{2}}{\left[a+a n^{*}\left(5+2 n^{*}\right)+n^{*}\left(n^{*}+n^{* 2}-1\right)\right]} \equiv c^{*} .
$$

Since $c^{\max ^{*}}=\frac{a}{2+n^{*}}$, we get that $c^{*}\left(0, c^{\max }\right)$, since $n \geq 1$.

The following proposition is then immediate.

Proposition 1: Entry is socially excessive (insufficient) in the presence of scale economies if $c<c^{*}\left(c \in\left(c^{*}, c^{\max ^{*}}\right)\right.$.

The intuition for the above result is as follows. As shown in Mankiw and Whinston (1986), entry of new firms steals business from the existing firms when the firms determine outputs simultaneously. However, this business stealing effect arises in our analysis only for the followers and not for the leaders. In fact, if the number of followers increases, it increases the output of the leader (see (5)). Hence, entry creates a positive output effect on the leader and this effect gets stronger with the marginal cost difference between the leader and the followers. On the other hand, if the marginal cost difference between the leader and the followers increases, it reduces the followers' incentive for entry and increasing market concentration. Hence, if the marginal cost difference is higher between the leader and the followers, the positive output effect of entry on the leader and the effect of higher market concentration dominate the negative business stealing effects of entry on the followers, thus 
creating insufficient entry. However, if the marginal cost difference between the leader and the followers is sufficiently small, the business stealing effects of entry on the followers is the dominant force and creates excessive entry.

Proposition 1 shows that, in the presence of scale economies, which are created by the fixed cost, $k$, entry may be either excessive or insufficient depending on the marginal cost difference between the leader and the followers. Now we will show the implication of scale economies by assuming $k=0$.

Proposition 2: If $k=0$, entry is always socially insufficient.

Proof: If $k=0$, we get from (8) that $n^{*}=\frac{a-2 c}{c}$. The socially optimal number of firms is found from (10) with $k=0$. We get that LHS of (10) is positive at $n^{*}$, which proves the result.

If there are no scale economies, entry of the followers occurs until the outputs of the followers are zero, which occurs at $n^{*}=\frac{a-2 c}{c}$. We get that the output of the leader at this free entry equilibrium number of firms is $q_{l}^{*}=a-c$, which is the perfectly competitive output at the marginal cost $c$. However, since the marginal cost of the leader is lower than $c$ and there is no cost of entry, welfare could be increased further with more followers than $n^{*}=\frac{a-2 c}{c}$, thus creating insufficient entry. Proposition 2 is in contrast to Ghosh and Saha (2007), which shows that entry is excessive in a Cournot oligopoly with no scale economies but with marginal cost differences. 


\subsection{The case of an open economy}

Like most of the literature, ${ }^{4}$ so far we have considered that all firms are from the same country, thus considering welfare effects of entry in a closed economy. However, given the wave of globalization where foreign competition plays an important role, the purpose of this section is to see how the above results change when the Stackelberg leader is a foreign firm. It should be noted that the identity of the Stackelberg leader, i.e. whether it is a foreign firm or a domestic firm, should not affect the entry decision of the followers. Hence, the free entry equilibrium number of firms is given by equation (8). However, if the Stackelberg leader is a foreign firm, it will affect the welfare maximization problem, since the profit of the leader will not appear in the welfare function. Hence, if the leader is a foreign firm, the domestic country maximizes its welfare, which is the sum of consumer surplus and the total profits of the Stackelberg followers, to determine the socially optimal number of followers. Hence, the domestic country maximizes the following expression:

$$
\operatorname{Max}_{n} \frac{(a-c(2+n))^{2}}{4(n+1)^{2}}+\frac{(a(2 n+1)-n c)^{2}}{4(n+1)^{2}}-n k .
$$

The socially optimal number of domestic followers is then determined from the following first order condition:

$$
\frac{a^{2}(2+n)-a c(5+3 n)+c^{2}[4+n(5+n(3+n))]}{4(n+1)^{3}}-k=0
$$

Straightforward calculation shows that LHS of (13) is positive at the free entry number of followers, given in (8). Hence, entry of the followers is insufficient for the domestic country.

If the Stackelberg leader is a foreign firm, its profit does not affect domestic welfare. Since more followers help to steal business from the Stackelberg leader, though they create

\footnotetext{
${ }^{4}$ Two exceptions are Lim (2010) and Marjit and Mukherjee (2010), which examine the excessive entry theory in an open economy under Cournot competition.
} 
business stealing effects among the followers, rent extraction from the foreign leader plays an important role and creates the socially optimal number of followers higher than the free entry equilibrium number of followers.

We have seen that entry is socially insufficient in a closed economy irrespective of the marginal cost difference between the leader and the followers if $k=0$. It can be shown that if $k=0$ and the Stackelberg leader is a foreign firm, rent extraction from the foreign leader provides further incentive for encouraging entry in the domestic country, thus creating insufficient entry in the domestic country.

We summarize the discussion of this section in the following proposition.

Proposition 3: If the Stackelberg leader is a foreign firm and the Stackelberg followers are domestic firms, entry in the domestic country is always socially insufficient, irrespective of the presence of scale economies.

\section{Conclusion}

The literature examining social efficiency of entry in oligopolistic markets is dominated by the consideration of Cournot oligopolies. However, the real life situation is often different, where some firms enjoy dominant positions in the market.

We use a simple model to examine social efficiency of entry in a Stackelberg leaderfollower structure. We show that entry in a closed economy is socially excessive (insufficient) in the presence of scale economies if the marginal cost difference between the leader and the followers is small (large), but it is always socially insufficient without scale economies. In an open economy with the foreign Stackelberg leader, entry is always socially insufficient. Our results show concern to the anti-competitive entry regulation policies 
following the previous literature showing socially excessive entry in Cournot oligopolies with homogeneous products and perfectly competitive input sector. 


\section{References}

Anderson, S.P., A. de Palma and Y. Nesterov, 1995, 'Oligopolistic competition and the optimal provision of products', Econometrica, 63, 1281-1301.

Cabral, L.M.B., 2004, 'Simultaneous entry and welfare', European Economic Review, 48, 943-57.

Dixit, A. and J. Stiglitz, 1977, 'Monopolistic competition and optimum product diversity', American Economic Review, 67, 297-308.

Etro, F., 2008, 'Stackelberg competition with endogenous entry', Economic Journal, 118: $1670-97$.

Fudenberg, D. and J. Tirole, 2000, 'Pricing a network good to deter entry', Journal of Industrial Economics, XLVIII, 373-90.

George, K. and A. Jacquemin, 1992, 'Dominant firms and mergers', Economic Journal, 102: 148-57.

Ghosh, A. and A. Morita, 2007a, 'Free entry and social efficiency under vertical oligopoly', Rand Journal of Economics, 38:539-52.

Ghosh, A. and A. Morita, 2007b, 'Social desirability of free entry: a bilateral oligopoly analysis', International Journal of Industrial Organization, 25: 925-34.

Ghosh, A. and S. Saha, 2007, 'Excess entry in the absence of scale economies', Economic Theory, 30: 575-86.

Klemperer, P., 1988, 'Welfare effects of entry into markets with switching costs', Journal of Industrial Economics, XXXVII, 159-65.

Landes, W. and R.A. Posner, 1981, 'Market power in antitrust cases', Harvard Law Review, 94: 937-83.

Lahiri, S. and Y. Ono, 1988, 'Helping minor firms reduces welfare', Economic Journal, 98, $1199-1202$. 
Lim, J.K.H., 2010, Essays in R\&D and competition policy in an open economy setting, $\mathrm{PhD}$ Thesis, University of New South Wales, Australia.

Mankiw, A.G. and M.D. Whinston, 1986, 'Free entry and social inefficiency’, RAND Journal of Economics, 17, 48-58.

Marjit, S. and A. Mukherjee, 2010, 'International trade cost reduction and domestic entry: the welfare implications, Mimeo, University of Nottingham, UK.

Martin, S., 2001, Industrial organization: a European perspective, Oxford University Press, New York, USA.

Mukherjee, A., 2007, 'Entry in a Stackelberg perfect equilibrium', Economics Bulletin, 12(33): 1-6.

Mukherjee, A., 2010, 'External economies of scale and insufficient entry', Journal of Industry, Competition and Trade (Forthcoming).

Mukherjee, A. and S. Mukherjee, 2008, 'Excess-entry theorem: the implications of licensing', The Manchester School, 76: 675-89.

Okuno-Fujiwara, M. and K. Suzumura, 1993, 'Symmetric Cournot oligopoly and economic welfare: a synthesis', Economic Theory, 3: 43-59.

Perry, M. K., 1984, 'Scale economies, imperfect competition, and public policy', Journal of Industrial Economics, 32: 313-33.

Scherer, F.M., 1980, Industrial market structure and economic performance, Rand McNally, Chicago.

Spence, A.M., 1976, 'Product selection, fixed costs, and monopolistic competition', Review of Economic Studies, 43: 217-36.

Suzumura, K., 1995, Competition, commitment ad welfare, Clarendon Press: Oxford.

Suzumura, K. and K. Kiyono, 1987, 'Entry barriers and economic welfare', The Review of Economic Studies, 54: 157-67. 
US Department of Justice, 1988, Merger guidelines, Trade Regulation Reports, CCH, at 20561.

Vives, X., 1988, 'Sequential entry, industry structure and welfare', European Economic Review, 32: 1671-87.

von Weizsäcker, C.C., 1980, 'A welfare analysis of barriers to entry', Bell Journal of Economics, 11: 399-420.

Williamson, O., 1968, 'Economies as an antitrust defense: welfare trade-offs', American Economic Review, 58: 18-36. 